OPEN ACCESS

Edited by:

Davide Zannoni,

University of Bologna, Italy

Reviewed by:

Shuhao Huo,

Jiangsu University, China

Saikat Chakraborty,

Indian Institute of Technology

Kharagpur, India

*Correspondence:

Fabian Abiusi

fabian.abiusi@gmail.com

Specialty section:

This article was submitted to

Extreme Microbiology,

a section of the journa

Frontiers in Microbiology

Received: 23 November 2021 Accepted: 06 January 2022

Published: 27 January 2022

Citation:

Abiusi F, Trompetter E, Pollio A, Wijfels RH and Janssen M (2022)

Acid Tolerant and Acidophilic

Microalgae: An Underexplored World of Biotechnological Opportunities.

Front. Microbiol. 13:820907.

doi: 10.3389/fmicb.2022.820907

\section{Acid Tolerant and Acidophilic Microalgae: An Underexplored World of Biotechnological Opportunities}

\author{
Fabian Abiusi ${ }^{1 *}$, Egbert Trompetter ${ }^{1}$, Antonino Pollio ${ }^{2}$, Rene H. Wijffels ${ }^{1,3}$ and \\ Marcel Janssen ${ }^{1}$
}

${ }^{1}$ Bioprocess Engineering, AlgaePARC, Wageningen University and Research, Wageningen, Netherlands, ${ }^{2}$ Department of Biology, University of Naples Federico II, Naples, Italy, ${ }^{3}$ Faculty of Biosciences and Aquaculture, Nord University, Bodø, Norway

Despite their large number and diversity, microalgae from only four genera are currently cultivated at large-scale. Three of those share common characteristics: they are cultivated mainly autotrophically and are extremophiles or tolerate "extreme conditions." Extreme growth conditions aid in preventing contamination and predation of microalgae, therefore facilitating outdoor cultivation. In search for new extremophilic algae suitable for largescale production, we investigated six microalgal strains able to grow at $\mathrm{pH}$ below 3 and belonging to four genera; Stichococcus bacillaris ACUF158, Chlamydomonas acidophila SAG 2045, and Chlamydomonas pitschmannii ACUF238, Viridiella fridericiana ACUF035 and Galdieria sulphuraria ACUF064 and ACUF074. All strains were cultivated autotrophically at light intensity of 100 and $300 \mu \mathrm{molm}^{-2} \mathrm{~s}^{-1}$ and $\mathrm{pH}$ between 1.9 and 2.9. The autotrophic biomass productivities were compared with one of the most productive microalgae, Chlorella sorokiniana SAG 211-8K, grown at pH 6.8. The acid tolerant strains have their autotrophic biomass productivities reported for the first time. Mixotrophic and heterotrophic properties were investigated when possible. Five of the tested strains displayed autotrophic biomass productivities 10-39\% lower than Chlorella sorokiniana but comparable with other commercially relevant neutrophilic microalgae, indicating the potential of these microalgae for autotrophic biomass production under acidic growth conditions. Two acid tolerant species, S. bacillaris and C. acidophila were able to grow mixotrophically with glucose. Chlamydomonas acidophila and the two Galdieria strains were also cultivated heterotrophically with glucose at various temperatures. Chlamydomonas acidophila failed to grow at $37^{\circ} \mathrm{C}$, while $\mathrm{G}$. sulphuraria ACUF64 showed a temperature optimum of $37^{\circ} \mathrm{C}$ and G. sulphuraria ACUF74 of $42^{\circ} \mathrm{C}$. For each strain, the biomass yield on glucose decreased when cultivated above their optimal temperature. The possible biotechnological applications of our findings will be addressed.

Keywords: extremophilic microalgae, biomass productivity, mixotrophy, biomass yield on substrate, temperature optima, Galdieria, Chlamydomonas acidophila, Stichococcus bacillaris 


\section{INTRODUCTION}

Microalgae are a diverse, polyphyletic group of organisms, boasting estimated species number between 2,00,000 and several million (Norton et al., 1996). In addition to cultivating microalgae for food and feed they also hold promise for a plethora of new products and applications. Microalgae are commonly grown exploiting their photoautotrophic capacity (henceforth referred to as autotrophic), in which cells harvest light energy, use carbon dioxide $\left(\mathrm{CO}_{2}\right)$ as a carbon source, and release oxygen $\left(\mathrm{O}_{2}\right)$ as a byproduct. Alternatives to autotrophic cultures are chemo-organotrophic (henceforth referred to as heterotrophic) cultures in which organic carbon, such as sugars and organic acids, are used as carbon sources in the absence of light. Despite the enormous diversity, only four genera of microalgae are cultivated at large-scale: Arthrospira (Spirulina), Chlorella, Dunaliella, and Haematococcus (Pulz and Gross, 2004). Excluding Chlorella, which is mainly produced heterotrophically in fermenters utilizing glucose or acetic acid (Iwamoto, 2004), the other three genera mentioned are cultivated mainly autotrophically and are extremophiles or tolerate "extreme conditions."

Extreme conditions are, for example, unusually high or low temperature, high or low $\mathrm{pH}$, or high osmotic pressure. If a strain has at least one of its growth optima falling into such a range, it is considered an extremophile, and if it has more than one optimum in such categories, the term is "polyextremophile." Spirulina is cultivated in alkaline media $(\mathrm{pH}$ 8.5-10.5), Dunaliella at high $\mathrm{NaCl}$ concentrations (35-300 g/L; Oren, 2014) and also Haematococcus can tolerate high salinity, which is used to promote accumulation of the red pigment astaxanthin within the cells (Oslan et al., 2021). Extreme growth conditions aid in preventing contamination and predation of microalgae, therefore facilitating their outdoor cultivation.

Bacterial contamination is a notable challenge when microalgae are cultivated in a medium containing organic carbon, as microalgae have a growth rate one order of magnitude lower than their competitors. In order to avoid bacterial contaminations, heterotrophic cultivation of microalgae is performed in bioreactors, where all inputs (liquid media or gasses) are sterilized and the process is optimized to operate axenically. With some microalgal species, autotrophic and heterotrophic cultivation can be combined in so-called "mixotrophic" cultivation. In this trophic mode, light and organic carbon are simultaneously provided and both heterotrophic and autotrophic metabolisms operate concurrently within a single microalgal monoculture. Mixotrophic cultivation can significantly increase biomass productivity and concentration, while utilizing light energy with the same photosynthetic efficiency of an autotrophic culture (Abiusi et al., 2020a,b).

When sunlight is used as a light source, mixotrophic cultivation of microalgae is performed in photobioreactors, characterized by high surface/volume ratio to maximize the light supply rate (Posten, 2009). Although it might be technically feasible to operate closed sunlit photobioreactors without bacterial contamination, maintaining axenic conditions in an outdoor photobioreactor, especially when a medium contains a source of organic carbon is challenging. In a pursuit of a strategy to prevent bacterial contamination under mixotrophic conditions, Henkanatte-Gedera et al. (2017) demonstrated that lowering $\mathrm{pH}$ of unsterilized urban primary effluent to a value of 2 resulted in a complete removal of pathogens and reduced the initial bacterial population by $98 \%$, allowing an acidophilic microalgae to be the primary organism growing in such a nutrient-rich medium. Contamination by unwanted microorganisms is not only a challenge in the presence of an organic substrate. There is a wide diversity of protist taxa (e.g., amoeba, flagellates, and ciliates) able to graze on microalgae, threatening the commercial success of the developing microalgal industry (Day et al., 2017). Several studies demonstrate that $\mathrm{pH}$ affects microbial community diversity more than any other parameter tested (Merino et al., 2019). Moreover, it is well documented that few ciliate and rotifer can survive $\mathrm{pH}$ below 3 (Seckbach, 2007).

During the last two decades, increasing attention has been paid toward acidophilic and acid tolerant microalgae and their possible biotechnological applications such as the production of acid stable pigments (Rahman et al., 2017; Ferraro et al., 2020a), rare earth metal biorecovery (Minoda et al., 2015), extremozymes (Rahman et al., 2020) and extremolytes (MartinezGarcia and van der Maarel, 2016). Despite their potential, most of the research on acidophilic microalgae has been focused on one species only: Galdieria sulphuraria (Sydney et al., 2019).

The aim of this study was to find microalgal strains able to grow at low $\mathrm{pH}$ sufficiently to exhibit potential for largescale production with or without utilizing organic carbon. In order to achieve this goal, we investigated the autotrophic biomass productivities of six acid tolerant microalgal strains at $\mathrm{pH}$ below 3 and compared their productivity with the neutrophilic Chlorella sorokiniana. Three strains were chosen since there were previous reports on their ability to use glucose, namely: Stichococcus bacillaris ACUF158, Chlamydomonas acidophila SAG 2045, and Chlamydomonas pitschmannii ACUF238 (Martinez et al., 1987; Pollio et al., 2005; Spijkerman, 2007). Viridiella fridericiana ACUF035 was suggested from the Algal Collection of University Federico II of Naples (ACUF) due to good autotrophic performance. Two strains of $G$. sulphuraria, the most studied acidophilic microalgae species, were compared with the acid tolerant strains. Galdieria sulphuraria ACUF064 and ACUF074 were selected based on the results of a screening of 42 Galdieria strains (Graziani et al., 2013) as they displayed the best autotrophic and heterotrophic growth rates. The acid tolerant microalgae strains performing well autotrophically were then also cultivated mixotrophically and, when possible, heterotrophically.

\section{MATERIALS AND METHODS}

\section{Organism, Media, and Cultivation Conditions}

Seven microalgal strains were used in this study. Stichococcus bacillaris ACUF158, C. pitschmannii ACUF238, V. fridericiana ACUF035, G. sulphuraria ACUF064, and G. sulphuraria ACUF074 
were obtained from the Algal Collection of University Federico II of Naples (ACUF). Chlamydomonas acidophila SAG 2045 and C. sorokiniana SAG 211-8K were obtained from the algae culture collection of Göttingen University (SAG). For each strain maintenance flasks were prepared. Maintenance cultures were cultivated autotrophically by placing $250 \mathrm{ml}$ flasks in an incubator with orbital shaker set at $100 \mathrm{rpm}$. Incubator headspace was enriched with $2 \% \mathrm{v} / \mathrm{v} \mathrm{CO}$ and the flasks were illuminated $24 / 24$ from the top by fluorescent lamps at a photon flux density (PFD) of $100 \mu \mathrm{mol} \mathrm{m}^{-2} \mathrm{~s}^{-1}$.

Chlorella sorokiniana SAG $211-8 \mathrm{~K}$ was cultivated at $\mathrm{pH}$ $6.8 \pm 0.1$ at $37^{\circ} \mathrm{C}$ in M8a medium (Abiusi et al., 2020a) with ammonium chlorine as a nitrogen source. All the other strains were cultivated initially at $\mathrm{pH} 2.1 \pm 0.2$ adjusting the $\mathrm{pH}$ with $2 \mathrm{M} \mathrm{H}_{2} \mathrm{SO}_{4}$. The medium was prepared according to Abiusi et al. (2021) composed of the following salts (in $\mathrm{molL}^{-1}$ ): $2.210^{-3} \mathrm{KH}_{2} \mathrm{PO}_{4}, 20.010^{-3}\left(\mathrm{NH}_{4}\right)_{2} \mathrm{SO}_{4}, 1.610^{-3} \mathrm{MgSO}_{4} 7 \mathrm{H}_{2} \mathrm{O}$, $0.110^{-3} \mathrm{CaCl}_{2}, 0.1610^{-3}$ EDTA ferric sodium salt, $0.0510^{-3}$ $\mathrm{Na}_{2}$ EDTA $2 \mathrm{H}_{2} \mathrm{O}, \quad 0.910^{-3} \quad \mathrm{NaCl}, \quad 0.210^{-3} \mathrm{H}_{3} \mathrm{BO}_{3}, \quad 20.210^{-6}$ $\mathrm{MnCl}_{2} 4 \mathrm{H}_{2} \mathrm{O}, 20.610^{-6} \quad \mathrm{ZnCl}_{2}, 8.010^{-6} \mathrm{CuSO}_{4} 5 \mathrm{H}_{2} \mathrm{O}, 4.110^{-6}$ $\mathrm{Na}_{2} \mathrm{MoO}_{4} 2 \mathrm{H}_{2} \mathrm{O}$, and $4.210^{-6} \mathrm{CoCl}_{2} 6 \mathrm{H}_{2} \mathrm{O}$. If no growth was observed, $\mathrm{pH}$ was increased to $2.9 \pm 0.2$. The two Galdieria strains were maintained at $37^{\circ} \mathrm{C}$, while the other acid tolerant strains were placed in two different incubators, set at 25 and $37^{\circ} \mathrm{C}$.

\section{Autotrophic Flasks Experiment}

In this study, we assessed the autotrophic performance of four acid tolerant microalgal strains, with a $\mathrm{pH}$ optimum above 3 but able to grow at $\mathrm{pH} 3$ or lower, namely: S. bacillaris ACUF158, C. acidophila SAG 2045, C. pitschmannii ACUF238, $V$. fridericiana ACUF035, and two acidophilic strains $G$. sulphuraria ACUF064 and G. sulphuraria ACUF074, with a pH optimum below 3 .

The autotrophic growth of these six microalgal strains was studied in $250 \mathrm{ml}$ flasks filled with $100 \mathrm{ml}$ of culture in a home-made incubator described by Abiusi et al. (2020a) and depicted in Figure 1. In this incubator illumination was provided 24/24 from below using warm-white LED at a PFD of $100 \pm 15$ and $300 \pm 25 \mu \mathrm{molm}^{-2} \mathrm{~s}^{-1}$. The position of each flask in the incubator was changed daily to minimize differences in light intensity within the incubator. Flasks were stirred at $100 \mathrm{rpm}$ with a magnetic rod and the headspace of the incubator was enriched with $4.5 \% \mathrm{v} / \mathrm{v} \mathrm{CO}_{2}$.

The four acid tolerant strains were cultivated at a temperature and $\mathrm{pH}$ in which growth was observed during the pre-cultivation summarized in Table 1. The two acidophilic G. sulphuraria strains were cultivated at $\mathrm{pH} 1.8 \pm 0.2$. In each experiment, $\mathrm{pH}$ was measured at the beginning and at the end of the experiment. The neutrophilic strain C. sorokiniana SAG 211-8K and the two G. sulphuraria strains were cultivated at $37^{\circ} \mathrm{C}$.

Each experiment was conducted in duplicate. Maintenance flasks were used as inoculum. Cultures were pre-cultivated using the maintenance flasks as inoculum and cultures were adapted to the respective light and temperature settings for at least 1 week. Provided that linear growth was observed during

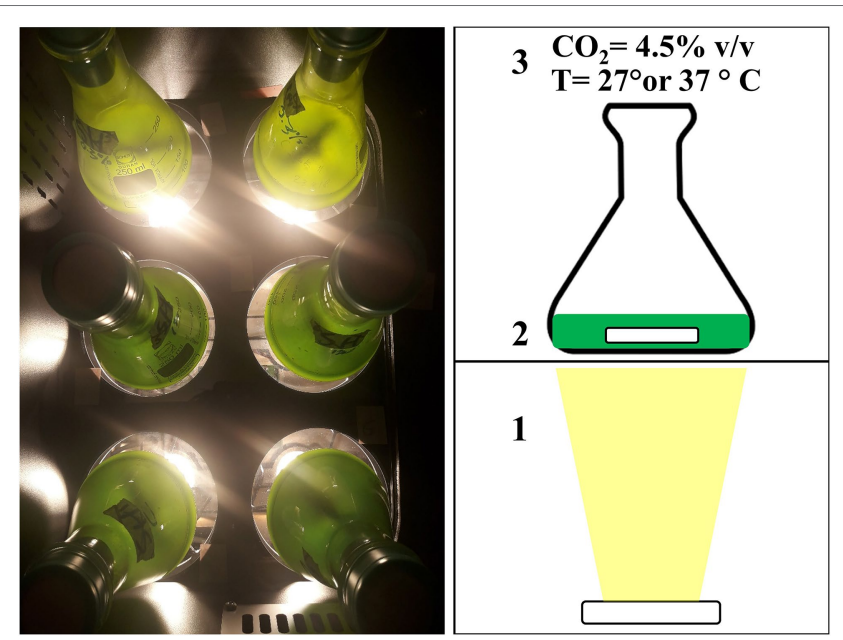

FIGURE 1 | Picture (left) and schematic view of the incubator used during the autotrophic experiment. Light was provided from below using a LED (1), flasks were stirred at $100 \mathrm{rpm}$ with a magnetic rod (2), and the head space of the incubator was enriched with $4.5 \% \mathrm{v} / \mathrm{v}$ carbon dioxide $\left(\mathrm{CO}_{2} ; 3\right)$.

Temperature of the incubator was maintained constant, either at $27^{\circ} \mathrm{C}$ or at $37^{\circ} \mathrm{C}$, depending on the experiment (3).

TABLE 1 | Temperature and $\mathrm{pH}$ used during the autotrophic experiment.

\begin{tabular}{llcc}
\hline Strain & pH optimum & pH & T (C) \\
\hline Chlorella sorokiniana SAG 211-8K & Neutrophilic & $6.8 \pm 0.1$ & 37 \\
Galdieria sulphuraria ACUF064 & Acidophilic & $1.9 \pm 0.2$ & 37 \\
Galdieria sulphuraria ACUF074 & Acidophilic & $2.0 \pm 0.2$ & 37 \\
Viridiella fridericiana ACUF035 & Acid tolerant & $2.1 \pm 0.2$ & 27 \\
Chlamydomonas acidophila SAG 2045 & Acid tolerant & $2.2 \pm 0.1$ & 27 \\
Stichococcus bacillaris ACUF158 & Acid tolerant & $2.9 \pm 0.3$ & 27 \\
Chlamydomonas pitschmannii ACUF238 & Acid tolerant & $2.8 \pm 0.2$ & 27 \\
& & & \\
\hline
\end{tabular}

The $\mathrm{pH}$ was measured at the beginning and at the end of the experiment and is reported with the $S D$ of the two measurements.

this adaptation time, the pre-culture was used as an inoculum for the actual autotrophic experiment starting at an optical density $1.2 \pm 0.3$ at $100 \mu \mathrm{mol} \mathrm{m}^{-2} \mathrm{~s}^{-1}$ and $4.5 \pm 1.2$ at $300 \mu \mathrm{mol} \mathrm{m}^{-2} \mathrm{~s}^{-1}$ measured at $750 \mathrm{~nm}\left(O D_{750}\right)$.

During the batch, one or two samples per day were taken from each flask to measure $O D_{750}$ and the photosystem II maximum quantum yield of photochemistry ( $Q Y$ or $\mathrm{Fv} / \mathrm{Fm}$ ). The microalgal concentration was assessed by converting $O D_{750}$ into biomass concentration $\left(C_{\mathrm{x}} \mathrm{g}_{\mathrm{x}} \mathrm{L}^{-1}\right)$, using $O D_{750} / C_{\mathrm{x}}$ linear correlation pre-determined for each strain and light intensity. The validity of this correlation was confirmed at the end of each experiment by an additional measurement of dry weight and optical density. The volumetric biomass production rate $r_{\mathrm{x}}\left(\mathrm{g}_{\mathrm{x}} \mathrm{L}^{-1} \mathrm{day}^{-1}\right)$ was calculated from a linear regression of the increase of biomass concentration $\left(C_{\mathrm{x}}\right)$ over time during the batch.

\section{Mixotrophic Microplate Experiment}

The ability of S. bacillaris ACUF158, C. acidophila SAG 2045, and $V$. fridericiana ACUF035 to grow mixotrophically utilizing glycerol, acetic acid, and glucose under 24/24 lighting was tested 
in 24-well microplates at $\mathrm{pH} 2.9 \pm 0.2$ (Costar 3524, Corning, United States). Glucose, acetic acid, and glycerol were supplemented to the autotrophic medium based on their carbon content. In order to provide $1 \mathrm{~g} \mathrm{~L}^{-1}$ of organic carbon, $2.75 \mathrm{~g} \mathrm{~L}^{-1}, 2.50 \mathrm{~g} \mathrm{~L}^{-1}$, and $2.56 \mathrm{~g} \mathrm{~L}^{-1}$ of glucose monohydrate, acetic acid, and glycerol were used. The mixotrophic performance was evaluated using an autotrophic culture grown under the same conditions in a medium without an organic carbon source as a reference.

Maintenance cultures were diluted to an $O D_{750}$ of $0.3-0.6$ with the specific media required and each well was filled with $1 \mathrm{ml}$ of this culture. Each medium was tested in triplicate. The 24-well plates were placed in an incubator at $25^{\circ} \mathrm{C}$, headspace was enriched with $2 \% \mathrm{v} / \mathrm{v} \mathrm{CO}_{2}$ and shaken at $100 \mathrm{rpm}$ (orbital shaker). Light was provided from the top by fluorescent lamps (Sylvania CF-LE $55 \mathrm{~W}$ ) giving a light intensity of $75 \mu \mathrm{mol} \mathrm{m}^{-2} \mathrm{~s}^{-1}$. Microalgal growth was followed by measuring $O D_{680}$ and $O D_{750}$ using a plate reader (Infinite Nanoquant M200, Tecan, Switzerland). The ratio $O D_{680} / O D_{750}$ was used as an indicator for the amount of chlorophyll per unit biomass and therefore of possible bacterial contaminations.

\section{Heterotrophic Flasks Experiment}

Chlamydomonas acidophila SAG 2045, G. sulphuraria ACUF064, and G. sulphuraria ACUF074, where cultivated heterotrophically under the same conditions used for the autotrophic experiment but supplementing the medium with $2.75 \mathrm{~g} \mathrm{~L}^{-1}$ glucose monohydrate without illumination. The experiment was conducted using the same procedure described by Abiusi et al. (2021). Several temperatures were tested. At each temperature cultures were adapted to heterotrophic growth for at least 2 weeks. Specific growth rate $(\mu)$ was calculated by plotting the natural logarithm of $O D_{750}$ over time of cultures growing exponentially.

During the experiments, multiple samples were taken per day until glucose was depleted. The concentration of microalgae was assessed by measuring optical density at $750 \mathrm{~nm}\left(O D_{750}\right)$. A $1 \mathrm{ml}$ aliquot of sample was centrifuged to obtain a clear supernatant for the glucose concentration measurement. The microalgae concentration was assessed by converting $O D_{750}$ into $C_{\mathrm{x}}$ using a $\mathrm{OD}_{750} / C_{\mathrm{x}}$ linear correlation pre-determined for each strain and temperature. The validity of this correlation was confirmed at the end of each experiment by an additional measurement of dry weight and optical density.

The heterotrophic biomass yield on substrate $\left(Y_{x / s}, \mathrm{~g}_{\mathrm{x}} \mathrm{g}_{s}^{-1}\right)$ was calculated using the following equation:

$$
Y_{x / s}=\frac{C_{x e}-C_{x 0}}{S_{0}-S_{e}}
$$

where $C_{\mathrm{x} 0} / C_{\mathrm{xe}}$ and $S_{0} / S_{\mathrm{e}}$ are the biomass and the glucose concentrations $\left(\mathrm{gL}^{-1}\right)$ respectively at the start and the end of the exponential phase.

\section{Analytical Methods}

The PFD $\left(\mu \mathrm{mol} \mathrm{m}^{-2} \mathrm{~s}^{-1}\right)$ was measured with a LI-COR 190-SA $2 \pi$ PAR quantum sensor and dry weight concentration $\left(C_{x}\right.$, $\left.\mathrm{g}_{\mathrm{x}} \mathrm{L}^{-1}\right)$, optical density at $750 \mathrm{~nm}\left(O D_{750}\right)$, and the photosystem II maximum quantum yield of photochemistry ( $Q Y$ or $\mathrm{Fv} / \mathrm{Fm})$ were determined according to Abiusi et al. (2020a). The presence of possible microbial contaminants was assessed both by optical and fluorescent microscopy after staining the sample with SYBER green I (Sigma-Aldrich, United States) according to Abiusi et al. (2020a).

Samples were taken aseptically from flasks one or two times per day. In the heterotrophic experiment, aliquots of $1 \mathrm{ml}$ were centrifuged at $20,000 \mathrm{rpm}(10 \mathrm{~min})$. The supernatant was immediately analyzed for glucose content. Glucose concentration was determined using a bioanalyzer (YSI 2700, YSI Life Sciences, United States) that couples an enzymatic reaction of glucose with electrochemical detection.

\section{Statistical Analysis}

Autotrophic and heterotrophic experiments were conducted in biological duplicate $(n=2)$, while mixotrophic experiment in biological triplicate $(n=3)$. Figures reported the SD of these replicates. Significant difference between strains cultivated in flasks under autotrophic and heterotrophic condition or between autotrophic and mixotrophic culture in microplate were analyzed by one-way ANOVA. The significance level was $p<0.05$.

\section{RESULTS}

\section{Autotrophic Growth}

Four acid tolerant and two acidophilic microalgae strains were tested for their autotrophic performance at two light intensities (100 and $300 \mu \mathrm{molm}^{-2} \mathrm{~s}^{-1}$ ) and compared to the neutrophilic C. sorokiniana SAG 211-8K. Maintenance cultures were prepared before initiating the experiment. These were kept at a $\mathrm{pH}$ $2.0 \pm 0.2$ at $37^{\circ} \mathrm{C}$. For the acid tolerant strains additional maintenance cultures were kept at $25^{\circ} \mathrm{C}$. At $\mathrm{pH} 2.0 \pm 0.2$ no growth was obtained in C. pitschmannii ACUF238 and $S$. bacillaris ACUF158 cultures regardless of the temperature applied. For this reason, the $\mathrm{pH}$ was increased to $2.9 \pm 0.2$. After the increase of $\mathrm{pH}$ those two strains succeeded in growing at $25^{\circ} \mathrm{C}$ but not at $37^{\circ} \mathrm{C}$. Viridiella fridericiana ACUF035 and C. acidophila SAG 2045 successfully grew at $\mathrm{pH} 2.1 \pm 0.2$ but no growth was observed at $37^{\circ} \mathrm{C}$. The presence in the medium of two buffers, by $\mathrm{H}_{3} \mathrm{PO}_{4} \rightleftharpoons \mathrm{H}_{2} \mathrm{PO}_{4}{ }^{-}+\mathrm{H}^{+}\left(\mathrm{pKa}_{1}=2.14\right)$ and $\mathrm{H}_{2} \mathrm{SO}_{4}+\mathrm{H}_{2} \mathrm{O} \rightleftharpoons \mathrm{H}^{+}+\mathrm{HSO}^{-}{ }_{4}\left(\mathrm{pK}_{\mathrm{al}}=1.92\right)$, maintained the $\mathrm{pH}$ stable across the experiments. Table 1 summarizes the final temperatures and $\mathrm{pH}$ used during the autotrophic experiment at two light intensities.

All of the tested strains succeeded in growing at $100 \mu \mathrm{mol} \mathrm{m}^{-2} \mathrm{~s}^{-1}$ (Figure 2; Supplementary Figures 1-7). No significant difference $(p<0.05)$ was found between the biomass productivities of S. bacillaris and C. sorokiniana $\left(0.6 \mathrm{~g} \mathrm{~L}^{-1} \mathrm{day}^{-1}\right)$, while the other five strains had a biomass productivity $25-72 \%$ lower than $C$. sorokiniana. When the strains were cultivated at $300 \mu \mathrm{molm}^{-2} \mathrm{~s}^{-1}, \quad$ C. pitschmannii did not grow and C. sorokiniana expressed the highest productivity $\left(1.1 \mathrm{gL}^{-1} \mathrm{day}^{-1}\right)$. The other five strains showed a productivity which was $10-39 \%$ lower than C. sorokiniana. Given the poor autotrophic 


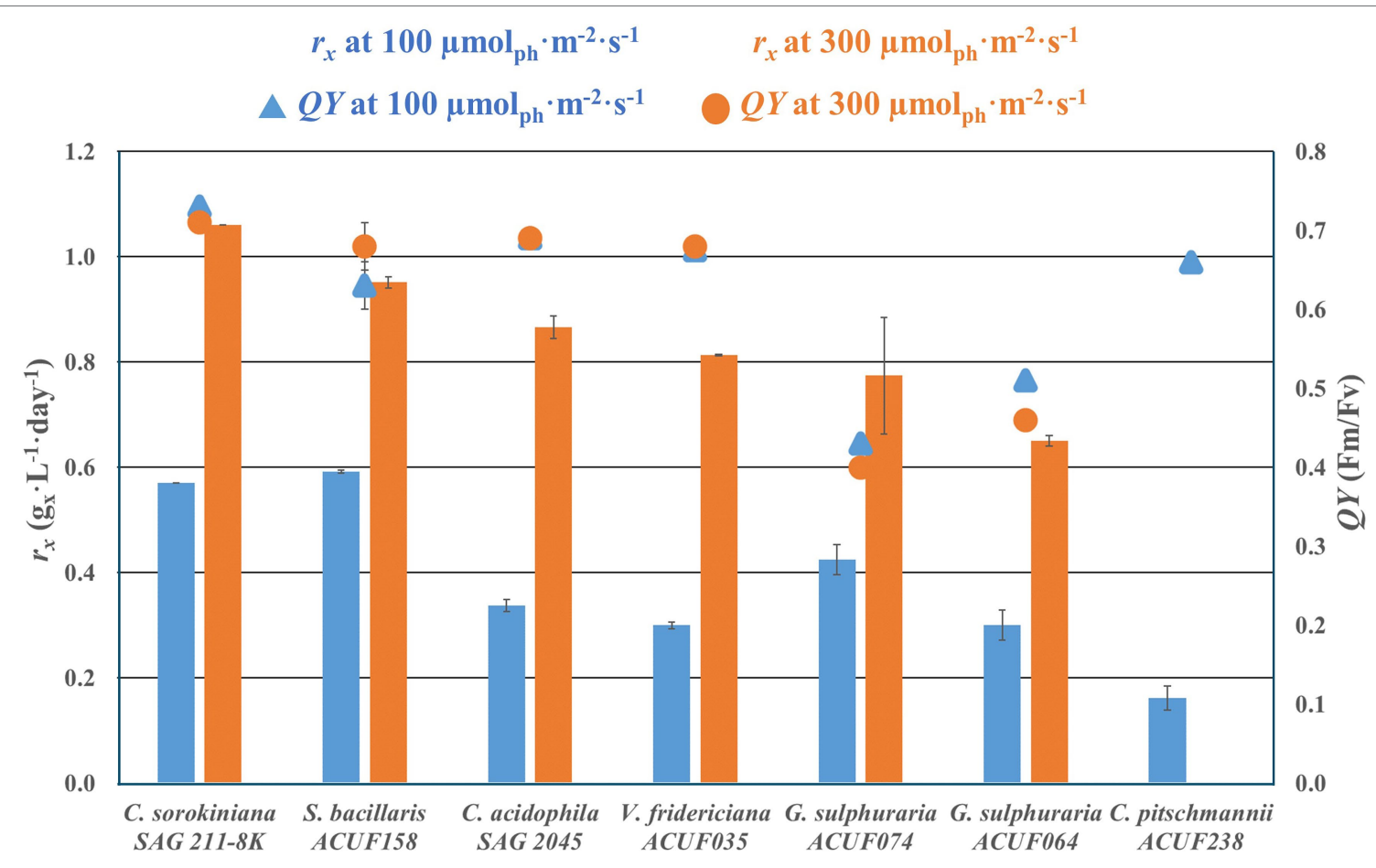

FIGURE 2 | Volumetric biomass production rate $r_{x}\left(g_{x} L^{-1}\right.$ day $\left.{ }^{-1}\right)$ and photosystem II maximum quantum yield of photochemistry $\left(Q Y, F_{v} / F_{m}\right)$ of autotrophic culture grown at 100 and $300 \mu \mathrm{molm}^{-2} \mathrm{~s}^{-1}$. The data are presented as average of the biological duplicate $(n=2)$ and reported with the SD of the measurements.

performance of C. pitschmannii, this strain was discontinued from further investigations.

The photosystem II maximum quantum yields of photochemistry were between 0.66 and 0.73 in C. sorokiniana and the acid tolerant strains with no significantly differences $(p<0.05)$ between 100 and $300 \mu \mathrm{mol} \mathrm{m}^{-2} \mathrm{~s}^{-1}$. At $100 \mu \mathrm{mol} \mathrm{m}^{-2} \mathrm{~s}^{-1}$, G. sulphuraria ACUF064 and G. sulphuraria ACUF074 had QY 30\% lower than other strains. The $Q Y$ of both strains significantly decreased $(p>0.05)$ further at $300 \mu \mathrm{molm}^{-2} \mathrm{~s}^{-1}$, resulting in a $Q Y$ of $0.46 \pm 0.1$ for $G$. sulphuraria ACUF064 and of $0.40 \pm 0.1$ for $G$. sulphuraria ACUF074.

\section{Mixotrophic Growth}

The ability of S. bacillaris ACUF158, C. acidophila SAG 2045, and $V$. fridericiana ACUF35 to utilize glucose, acetic acid, and glycerol in presence of light was tested on 24-well microplates (Figure 3). The final $O D_{750}$ reached for S. bacillaris ACUF158 and C. acidophila SAG 2045 grown in presence of glucose was significantly higher than the autotrophic cultures grown under similar conditions. In both strains $O D_{680} / O D_{750}$ remained constant suggesting that the cultures were axenic and that glucose boosted algal growth. Microscopic observation from samples taken at the end of the experiment confirmed axenicity (Supplementary Figures 8-10). Viridiella fridericiana ACUF35 was growing similarly in the presence of glucose as the corresponding autotrophic culture indicating that the culture was not able to utilize this substrate. Glycerol did not have any effect on the three tested strains, while acetic acid was lethal for all of them.

\section{Heterotrophic Growth}

Heterotrophic experiments were conducted with C. acidophila SAG 2045, G. sulphuraria ACUF064, and G. sulphuraria ACUF074 to determine specific growth rate $(\mu)$ and biomass yield on substrate $\left(Y_{x / s}\right)$ using glucose. Cultures were adapted for 2 weeks before starting the experiment under heterotrophic conditions. During this adaptation period, the cultures were diluted regularly with fresh medium to maintain exponential growth. During the adaptation time, all the cultures lost their pigmentation and became pale. Chlamydomonas acidophila cultivated at $25^{\circ} \mathrm{C}$ had a specific growth rate of $0.52 \mathrm{day}^{-1}$ and a biomass yield on substrate of $0.4 \mathrm{~g}_{\mathrm{x}} \mathrm{g}_{\mathrm{s}}^{-1}$, while no growth was observed at $37^{\circ} \mathrm{C}$ (Figure 4).

The two G. sulphuraria strains grown at $37^{\circ} \mathrm{C}$ had similar specific growth rates and biomass yields on substrate, $0.75 \mathrm{day}^{-1}$ and $0.5 \mathrm{~g}_{\mathrm{x}} \mathrm{g}_{\mathrm{s}}^{-1}$ (Figure 4). When temperature was increased to $42^{\circ} \mathrm{C}$ the specific growth rate of G. sulphuraria ACUF064 decreased to 0.33 day $^{-1}$, while the specific grow rate of $G$. sulphuraria ACUF074 increased to 1.04 day $^{-1}$ to decline again to $0.41 \mathrm{day}^{-1}$ at $47^{\circ} \mathrm{C}$. For each strain, the biomass yield on glucose decreased as soon as it was cultivated above its optimal temperature.

\section{DISCUSSION}

In the present study six microalgal strains, belonging to four different microalgal genera, were cultivated autotrophically at a $\mathrm{pH}$ below 3, under similar conditions. The autotrophic 

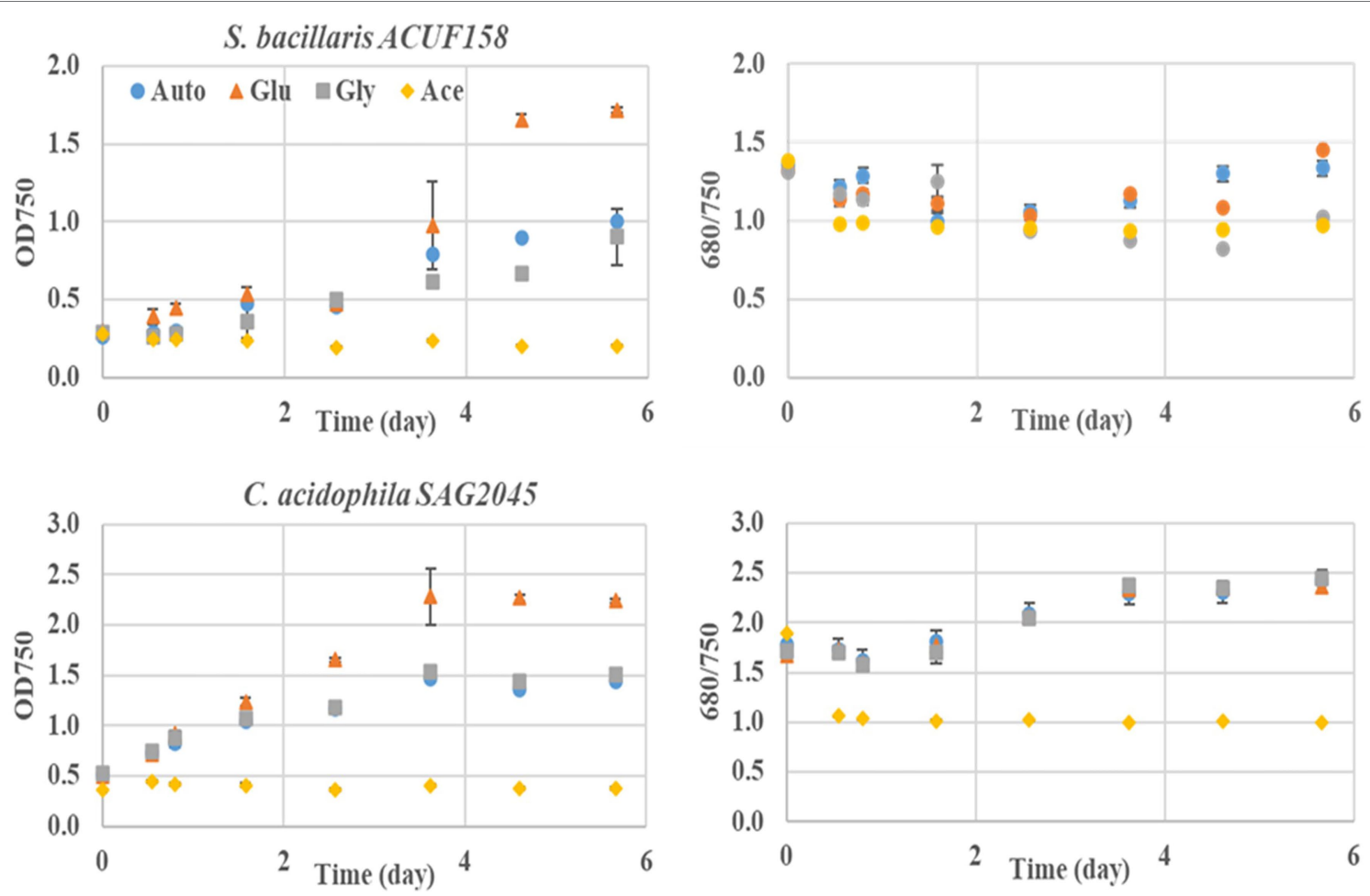

V. fredericiana ACUF 035
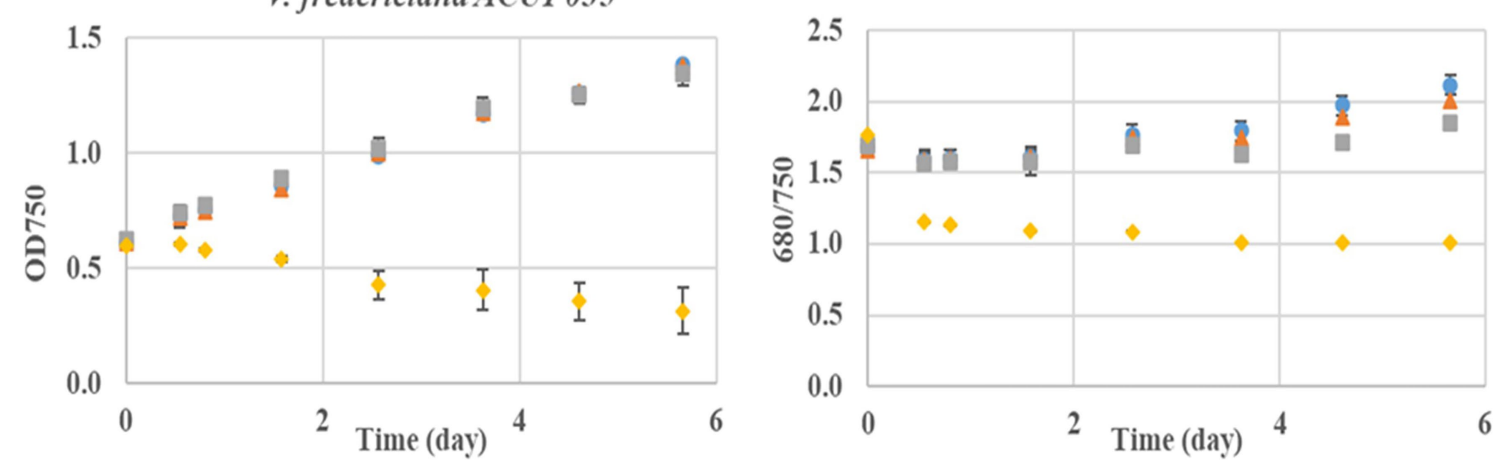

FIGURE 3 | Mixotrophic performance in the presence of $1 \mathrm{~g} / \mathrm{L}$ of individual carbon source such as glucose (triangle), glycerol (square), and acetic acid (diamond) of three acid tolerant microalgal cultivated at $\mathrm{pH} 2.9 \pm 0.2$ strains under 24/24 lighting. An autotrophic culture (dot) is used as reference.

performances of those six microalgal strains were compared with neutrophilic C. sorokiniana SAG $211-8 \mathrm{~K}$, which is one of the fastest growing microalgae (Cuaresma et al., 2009). Five of the tested strains showed an autotrophic biomass productivity which was $10-39 \%$ lower than C. sorokiniana but comparable with other commercially relevant neutrophilic microalgae such as Isocrysis lutea (Gao et al., 2020), Rhodomonas sp. (Oostlander et al., 2020), and Nannochloropsis sp. (Benvenuti et al., 2016) indicating the potential of these microalgae for autotrophic biomass production under acidic growing conditions.

Literature concerning autotrophic productivity of acid tolerant microalgae grown below $\mathrm{pH} 3$ is limited. Most studies on acid tolerant microalgae isolated from acid waters are not focusing on biomass production but were conducted from taxonomic (Albertano et al., 1991, 2000), evolutionary
(Costas et al., 2007), or ecological viewpoints (Aguilera et al., 2007). In the present work, autotrophic biomass productivities of the studied acid tolerant strains are reported for the first time. One of the few previous works on biomass productivity of an acid tolerant microalgae was conducted by Cuaresma et al. (2011) in a $1 \mathrm{~L}$ photobioreactor. The authors cultivated a newly isolated acid tolerant $C$. acidophila strain at $\mathrm{pH} 2.5$ obtaining a biomass areal productivity of $20 \mathrm{~g} \mathrm{~m}^{-2} \mathrm{day}^{-1}$. The acid tolerant strains used in our study displayed a biomass areal productivity of $15-18 \mathrm{~g} \mathrm{~m}^{-2}$ day $^{-1}$ when cultivated at $300 \mu \mathrm{mol} \mathrm{m}^{-2} \mathrm{~s}^{-1}$. Those areal productivities were derived from the volumetric productivity considering the bottom of the flask as illuminated surface (Figure 1). The resulting areal productivities obtained in flasks with the two G. sulphuraria strains are comparable to the productivities observed in our 


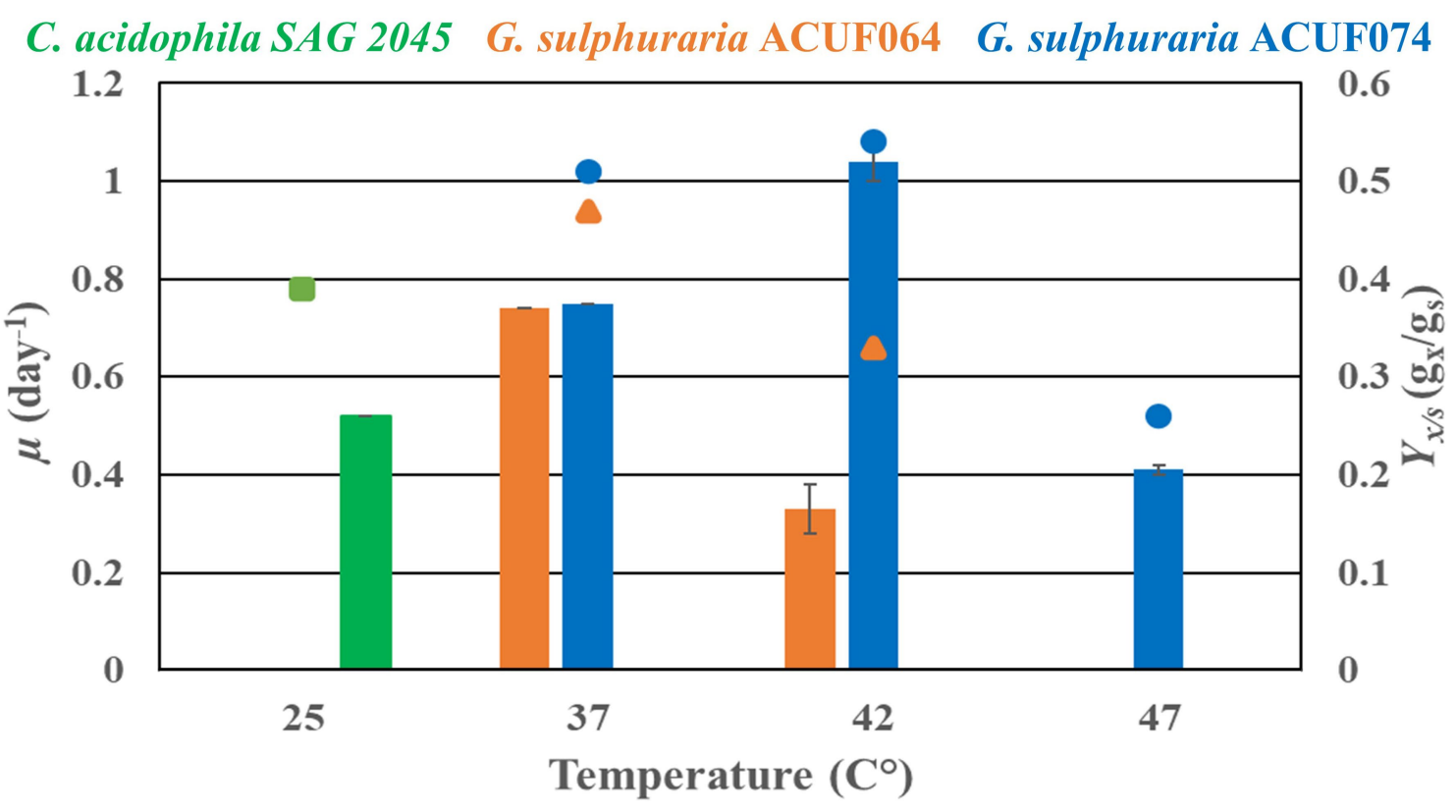

FIGURE 4 | Heterotrophic specific growth rate $(\mu)$ and biomass yield substrate $\left(Y_{x / s}\right)$ of Chlamydomonas acidophila SAG 2045 (green), Galdieria sulphuraria ACUF064 (orange), and Galdieria sulphuraria ACUF074 (blue) grown on glucose at different temperatures.

two recent studies in a $2 \mathrm{~L}$ photobioreactor (Abiusi et al., 2021, 2022). The data obtained from our flask incubator (Figure 1) therefore represents cultivation in a bench-scale photobioreactor. This is due to the specific setup of our experiment where algae, grown in flasks at a controlled temperature and elevated $\mathrm{CO}_{2}$, are illuminated from below which leads to a high surface/ volume ratio $\left(50.3 \mathrm{~m}^{-1}\right)$ and a high light supply rate. The high light regime can also explain why linear growth was maintained until a high biomass concentration of $9 \mathrm{gL}^{-1}$ was reached (Supplementary Figures 1-6).

Other studies on acid tolerant strains often report only the autotrophic specific growth rate $(\mu)$ measured in the exponential growth phase (Gerloff-Elias et al., 2005; Olivieri et al., 2011). Although, the specific growth rate is not sufficient to predict biomass productivity, it may be used to compare different conditions and to give a first indication of the autotrophic growth potential of the strain. Olivieri et al. (2011) studied the autotrophic growth rate of $S$. bacillaris ACUF158 at $\mathrm{pH}$ $3.3,6$, and 8.3. In their study, S. bacillaris ACUF158 displayed a $\mathrm{pH}$ optimum of 6 with a $\mu$ of $0.79 \mathrm{day}^{-1}$, while at $\mathrm{pH} 3.3$ it was reduced to $0.33 \mathrm{day}^{-1}$. In our experiments, $S$. bacillaris was cultivated at $\mathrm{pH}$ similar to the lowest $\mathrm{pH}$ tested by Olivieri et al. (2011) and we observed a similar growth rate.

In the only previous study on C. acidophila SAG 2045 (Gerloff-Elias et al., 2005), the authors reported two autotrophic $\mathrm{pH}$ optimums at $\mathrm{pH} 3$ and 5 with maximum specific growth rate of $0.8 \mathrm{day}^{-1}$. Gerloff-Elias et al. (2005) compared C. acidophila SAG 2045 at $\mathrm{pH} 3$ and 5 to the neutrophilic Chlamydomonas reinhardtii SAG 11-32b grown at neutral $\mathrm{pH}$ reporting similar growth rate. The higher dark respiration rates found in $C$. acidophila were compensated by higher photosynthetic rates.
The poorest autotrophic performance in our experiment was observed from C. pitschmannii ACUF238. The only previous study on C. pitschmannii ACUF238 regards the eco-physiological characterization and isolation of the strain (Pollio et al., 2005). Growth optimum at $\mathrm{pH} 2.5$ and temperature $37^{\circ} \mathrm{C}$ were found, while in our study the strain failed to grow under such conditions. Large intraspecific variations in key ecophysiological traits are common within natural populations. The C. pitschmannii strains were isolated by serial dilution from the site of Pisciarelli in mid-2003 and were immediately used for the experiments reported in Pollio et al. (2005). During long-term maintenance in the following 18 years, the strains have been treated against bacteria and fungi contamination and re-isolated. The combination of high nutrient concentrations provided by the culture media and the stability of light and temperature conditions $\left(60 \mu \mathrm{mol} \mathrm{m}^{-2} \mathrm{~s}^{-1}\right.$ and $24 \pm 1^{\circ} \mathrm{C}$, respectively) could have led to a laboratory selection of neutrophilic isolates with a temperature optimum closer to $25^{\circ} \mathrm{C}$ possibly explaining the disparities between the studies.

Another important observation in our work is that two acid tolerant species, C. acidophila SAG 2045 and S. bacillaris ACUF158, were able to grow mixotrophically with glucose displaying a higher growth rate than the corresponding autotrophic culture. In a previous study by Cuaresma et al. (2011), C. acidophila was cultivated mixotrophically without $\mathrm{CO}_{2}$ addition using acetic acid, glycerol, glucose, glycine, or starch as the sole carbon source. Chlamydomonas acidophila was able to utilize the tested organic substrates, except for acetic acid, but the growth rate and final biomass produced were significantly lower than, or in the case of glucose, similar, to the autotrophic control. A different strain used in our study may explain the variance between our results 
and Cuaresma et al. (2011). Our recent studies demonstrated that mixotrophy is a promising strategy to even double the biomass productivity (Abiusi et al., 2020b, 2021). Mixotrophic production of microalgae is already used at industrial scale to decrease microalgal production costs (Iwamoto, 2004; Ganuza and Tonkovich, 2016). We believe that mixotrophic cultivation of acid tolerant and acidophilic microalgae, by reducing the risk of contamination, will further facilitate this cultivation strategy.

We further studied glucose assimilation cultivating C. acidophila SAG 2045 under strictly heterotrophic conditions (no light) at $25^{\circ} \mathrm{C}$. The heterotrophic specific growth rate $(\mu)$, we observed in this study $\left(0.52\right.$ day $\left.^{-1}\right)$ was comparable with the autotrophic $\mu$ of 0.72 day $^{-1}$ observed by Gerloff-Elias et al. (2006) at $25^{\circ} \mathrm{C}$. In the same study, the temperature optimum of $C$. acidophila SAG 2045 was reported to be $20^{\circ} \mathrm{C}$ with a drop of $25 \%$ in $\mu$ at $25^{\circ} \mathrm{C}$. Suboptimal temperature might also explain the low biomass yield on substrate $\left(Y_{x / s}\right)\left(0.39 \mathrm{~g}_{\mathrm{x}} \mathrm{g}_{s}{ }^{-1}\right)$ found in our study. In fact, a $Y_{x / s}$ of $0.7 \mathrm{~g}_{x} \mathrm{~g}_{s}^{-1}$ has been previously reported in other Chlymidomonas species (Chen and Johns, 1996). Biomass yield on glucose is known to decrease as soon as the temperature optimum is exceeded, as also confirmed by the two Galdieria strains (Figure 4).

Glucose also increased the growth rate of S. bacillaris ACUF158 under mixotrophic conditions. Martinez et al. (1987) isolated a $S$. bacillaris from a sugar factory and reported that the mixotrophic growth rate was about $70 \%$ higher than autotrophic growth rate. Moreover, the same authors indicated that, when cultivated at neutral $\mathrm{pH}$ S. bacillaris could use sucrose, fructose, citrate, and acetate as carbon sources. At $\mathrm{pH} 3$ in our mixotrophic experiments, acetic acid was lethal to all tested species. This was expected since acetic acid has a $\mathrm{pKa}$ of 4.76 , so in our medium at $\mathrm{pH} 3$ it was mainly present in the protonated form. Acetic acid can therefore enter the cell through passive diffusion. Once inside the cell, where the $\mathrm{pH}$ is close to neutrality, the undissociated acetic acid causes intracellular acidification. To counteract this acidification, protons have to be pumped out of the cells dissipating the proton motive force across the plasma membrane (Guldfeldt and Arneborg, 1998).

The most studied acidophilic microalgae species is G. sulphuraria with a growing research interest observed in the last decade (Sydney et al., 2019). Galdieria sulphuraria has been proposed as a novel source of protein (Abiusi et al., 2022), dietary fibers (Graziani et al., 2013), antioxidants (Carfagna et al., 2016) and of the blue pigment C-phycocyanin (Wan et al., 2016). For a long time, G. sulphuraria has been considered extremely photosensitive with light inhibition occurring at intensities above $200 \mu \mathrm{mol} \mathrm{m}^{-2} \mathrm{~s}^{-1}$ (Brock, 1978; Sloth et al., 2006) recently it was demonstrated (Abiusi et al., 2021); however, that G. sulphuraria ACUF064 can be cultivated at high light intensity by optimizing the specific light supply rate. This was done by optimizing the biomass concentration in the reactor (Abiusi et al., 2021). In the present work. we cultivated two G. sulphuraria strains at 100 and $300 \mu \mathrm{mol} \mathrm{m}^{-2} \mathrm{~s}^{-1}$ and started the experiment at biomass concentrations of $0.9 \mathrm{gL}^{-1}$ and $1.5 \mathrm{gL}^{-1}$, respectively (Supplementary Figures 5, 6). At these biomass concentrations, the specific light supply rate was below $9.5 \mu \mathrm{mol}_{\mathrm{ph}} \mathrm{g}_{\mathrm{x}}^{-1} \mathrm{~s}^{-1}$, the upper limit previously reported for photoinhibition (Abiusi et al., 2021). Absence of photoinhibition was confirmed by the photosystem II maximum quantum yield ( $Q Y, \mathrm{Fv} / \mathrm{Fm})$ which was in a higher range reported for G. sulphuraria (Abiusi et al., 2021; Uwizeye et al., 2021). Moreover, linear growth was observed from the first day (Supplementary Figures 5, 6) further confirming the adaptation of those strains for both the light intensities applied. These results obtained with two strains, confirm that $G$. sulphuraria can successfully be cultivated autotrophically at a high light intensity with a good biomass productivity.

Graziani et al. (2013) performed the largest screening ever performed on G. sulphuraria, comparing autotrophic and heterotrophic specific growth rates of 42 strains belonging to ACUF. In the autotrophic screening, the G. sulphuraria strains were cultivated at $\mathrm{pH} 1.5,36^{\circ} \mathrm{C}$ without $\mathrm{CO}_{2}$ addition and the medium contained only $40 \mathrm{mg} \mathrm{L}^{-1}$ of nitrogen, 14 times lower than the nitrogen concentration used in our work. Heterotrophic cultivation was conducted using $3 \%$ glycerol as the source of organic carbon. Galdieria sulphuraria ACUF064 was the best performing strain under both autotrophic and heterotrophic conditions. Galdieria sulphuraria ACUF064 had a similar autotrophic $\mu$ as G. sulphuraria ACUF074 but under heterotrophic conditions, the $\mu$ of G. sulphuraria ACUF064 was the double of $G$. sulphuraria ACUF074, 1.0 day $^{-1}$ and $0.5 \mathrm{day}^{-1}$, respectively. The difference in heterotrophic $\mu$ between our study and Graziani et al. (2013), may be explained by different growing conditions (e.g., medium composition, organic substrate).

The lack of standardized procedures in the screening of acid tolerant and acidophilic microalgae was the main cause of the discrepancies between our findings and the previous studies. Moreover, previous studies mainly measured the specific growth rate $(\mu)$, which is not sufficient to predict bulk growth at biomass concentrations used in large scale production. Commercial production of microalgae is better characterized by linear growth, such as volumetric $\left(\mathrm{gL}^{-1} \mathrm{day}^{-1}\right)$ or areal $\left(\mathrm{g} \mathrm{m}^{-2}\right.$ day $\left.^{-1}\right)$ productivity. Van Wagenen et al. (2014) proposed a microplate-based method for high-throughput screening of microalgae, based on the measurement of two input parameters: specific growth rate as a function of light intensity and light absorbance coefficient. Using these two inputs it was possible to predict the volumetric biomass productivity. This type of a high-throughput screening procedures can offer a solution to obtain industrially relevant information on algal strains. Despite hundreds of microalgal strains able to grow at $\mathrm{pH}$ below 3 having been isolated (D'Elia et al., 2018) and kept at culture collections, information on the biomass productivities of these strains are limited to a few. Standardized high-throughput screenings are required to exploit the potential of unexplored groups of microalgae.

\section{Future Outlook}

In this study, we demonstrated that microalgae cultivated at $\mathrm{pH}$ below 3 can have biomass productivities comparable to neutrophilic strains. In this section, we will discuss possible 
advantages and biotechnological applications of acid tolerant and acidophilic microalgae.

Biomass productivity of an illuminated algal culture can be doubled by utilizing a mixotrophic cultivation strategy (Abiusi et al., 2020a, 2022). In the current study, two acid tolerant strains, C. acidophila SAG 2045 and S. bacillaris ACUF158, demonstrated an increased growth rate when cultivated in the presence of glucose, while G. sulphuraria is known to be able to grow mixotrophically on glucose and glycerol (Sloth et al., 2006). Mixotrophic cultivation of those acid tolerant and acidophilic strains is expected to further increase biomass productivity making them more productive than most of the neutrophilic microalgal strains cultivated autotrophically. When neutrophilic microalgae are cultivated in presence of organic substrate, contamination by heterotrophic bacteria and fungi is a considerable challenge (Unnithan et al., 2014). Contaminating microbes have a growth rate faster than microalgae and can therefore outcompete algae for organic carbon utilization. Cultivating microalgae at low $\mathrm{pH}$ can be a worthwhile strategy to prevent contaminants. Previous works indicated that G. sulphuraria can be cultivated axenically in a lab scale mixotrophic reactor for over a month (Abiusi et al., 2021, 2022). Another work reports that at $\mathrm{pH} 2$ G. sulphuraria was the main organism growing in unsterilized primary municipal waste water (Henkanatte-Gedera et al., 2017). Moreover, the low $\mathrm{pH}$ reduced the initial bacterial population by $98 \%$ and removed all the pathogens originally present in the waste water. Therefore, cultivation of microalgae at low $\mathrm{pH}$ might offer a means to bioremediate urban waste water (di Cicco et al., 2021) or valorize agro-industrial side streams (Scherhag and Ackermann, 2020), while minimizing the risk of contaminations by unwanted microorganisms.

Acid tolerant and acidophilic microalgae are often found in mining effluents characterized by low $\mathrm{pH}$ and high concentration of heavy metals (Dean et al., 2019). One exciting application is the use of those microalgae in rare earth metal biorecovery (Minoda et al., 2015). Numerous metals, including rare earth elements, can be readily dissolved in aqueous acid and selectively bioaccumulated in acidophilic microalgae from which they are then recovered.

Extremophilic organisms have also received increasing attention for the production of metabolites and enzymes that are commercially relevant for chemical, pharmaceutical, and food industries. Extremophiles have already been used for the production of extremozymes able to catalyze chemical reactions at an unusually high or low $\mathrm{pH}$, temperature, or pressure. Such enzymes broaden the operational range of bioprocesses. Recently, the presence glucoamylases active at $\mathrm{pH} 2-2.5$ and $80^{\circ} \mathrm{C}$ have been demonstrated in G. sulphuraria (Rahman et al., 2020). In the whole genome analysis of G. sulphuraria, a range of genes with high similarity with other extremozymes have been identified (Shrestha and Weber, 2007), which gives an indication that extremophilic microalgae can be used as a source extremozymes.

Extremophiles can also be used to produce extremolytes (Malavasi et al., 2020), small organic molecules, which allow extremophiles to withstand their extreme environments. They might have bioactive properties usable for medical purposes and in food industry (Becker and Wittmann, 2020). Floridoside is a glycoside accumulated by almost all red algae, including G. sulphuraria, under a high osmotic pressure (MartinezGarcia and van der Maarel, 2016). This compound has been proposed for preventing biofouling in aquaculture (Callow and Callow, 2002), as a potential therapeutic agent to modulate immune response (Kim et al., 2013) and to promote bone formation (Ryu et al., 2015). The development of industrial applications for floridoside is hindered by low availability. Galdieria sulphuraria is demonstrated to accumulate high concentration of this compound and is a promising organism for industrial production of floridoside (Martinez-Garcia and van der Maarel, 2016).

Finally, acidophilic microalgae have been envisaged as novel source of pigments such as lutein (Cuaresma et al., 2011) and C-phycocyanin (Abiusi et al., 2022). C-phycocyanin extracted from several members of the cyanidiales family, known acid and thermophilic organisms, have reportedly exceptional thermoand acid stability (Rahman et al., 2017; Ferraro et al., 2020a). The higher stability compared to the C-phycocyanin of other microalgae (e.g., Spirulina) is due to a residue mutation on the outside of the conserved regions (Ferraro et al., 2020b). Those traits open the opportunity to use said pigments in commonly pasteurized sparkling beverages, characterized by a low $\mathrm{pH}$.

Acid tolerant and acidophilic microalgae have applications in several industrial processes such as the ones listed in this section. However, most of the current knowledge on possible new products and applications comes almost solely from studies conducted on G. sulphuraria. The combination of high throughput screening and omics techniques can be employed to select new productive strains as source of high value compounds.

\section{CONCLUSION}

In the present study, six microalgal strains were cultivated at a $\mathrm{pH}$ below 3. Utilizing acid growth conditions is a strategy to prevent unwanted microbial contaminations in autotrophic and specifically mixotrophic microalgae cultivation. Five of the tested strains showed an autotrophic biomass productivity comparable with other commercially relevant neutrophilic microalgae, indicating the potential of these microalgae for autotrophic biomass production. Two strains were also able to grow mixotrophically on glucose displaying higher growth rates than the corresponding autotrophic cultures. The ability to grow heterotrophically on glucose was tested on three strains. All of the strains grown heterotrophically lost their pigmentation in the darkness and displayed a specific growth rate between 0.5 and 1 day $^{-1}$, comparable to other commercially relevant microalgal species. Due to the reduced risk of microbial contaminations and biomass productivity comparable to neutrophilic microalgae, acid tolerant, and acidophilic microalgae are promising candidates for mass cultivation. 
DATA AVAILABILITY STATEMENT

The raw data supporting the conclusions of this article will be made available by the authors, without undue reservation.

\section{AUTHOR CONTRIBUTIONS}

FA designed and conducted experiments, analyzed and interpretated the data, and drafted the manuscript. ET conducted a part of the experiments and analyzed the corresponding data. AP provided the strains and assisted with interpretation of the data. RW obtained funding and assisted with interpretation of the data. MJ contributed to the design of the experiments, interpreted data, and drafted the manuscript.

\section{REFERENCES}

Abiusi, F., Fernández, P. M., Canziani, S., Janssen, M., Wijffels, R. H., and Barbosa, M. (2022). Mixotrophic cultivation of Galdieria sulphuraria for C-phycocyanin and protein production. Algal Res. 61:102603. doi: 10.1016/j. algal.2021.102603

Abiusi, F., Trompetter, E., Hoenink, H., Wijffels, R. H., and Janssen, M. (2021). Autotrophic and mixotrophic biomass production of the acidophilic Galdieria sulphuraria ACUF 64. Algal Res. 60:102513. doi: 10.1016/j.algal.2021.102513

Abiusi, F., Wijffels, R. H., and Janssen, M. (2020a). Doubling of microalgae productivity by oxygen balanced mixotrophy. ACS Sust. Chem. Eng. 8, 6065-6074. doi: 10.1021/acssuschemeng.0c00990

Abiusi, F., Wijffels, R. H., and Janssen, M. (2020b). Oxygen balanced mixotrophy under day-night cycles. ACS Sust. Chem. Eng. 8, 11682-11691. doi: 10.1021/ acssuschemeng.0c03216

Aguilera, A., Zettler, E., Gómez, F., Amaral-Zettler, L., Rodríguez, N., and Amils, R. (2007). Distribution and seasonal variability in the benthic eukaryotic community of Río Tinto (SW, Spain), an acidic, high metal extreme environment. Syst. Appl. Microbiol. 30, 531-546. doi: 10.1016/j. syapm.2007.05.003

Albertano, P., Ciniglia, C., Pinto, G., and Pollio, A. (2000). The taxonomic position of Cyanidium, Cyanidioschyzon and Galdieria: an update. Hydrobiologia 433, 137-143. doi: 10.1023/A:1004031123806

Albertano, P., Pinto, G., Pollio, A., and Taddei, R. (1991). Physiological, biochemical, and ultrastructural characters of some strains of Viridiella fridericiana (Chlorophyta, Chlorococcales). Arch. Protistenkd. 139, 117-123. doi: 10.1016/S0003-9365(11)80013-8

Becker, J., and Wittmann, C. (2020). Microbial production of extremolyteshigh-value active ingredients for nutrition, health care, and well-being. Curr. Opin. Biotechnol. 65, 118-128. doi: 10.1016/j.copbio.2020.02.010

Benvenuti, G., Lamers, P. P., Breuer, G., Bosma, R., Cerar, A., Wijffels, R. H., et al. (2016). Microalgal TAG production strategies: why batch beats repeatedbatch. Biotechnol. Biofuels 9:64. doi: 10.1186/s13068-016-0475-4

Brock, T. D. (1978). Thermophilic Microorganisms and Life at High Temperatures. New York, NY: Springer, 255-302.

Callow, M. E., and Callow, J. E. (2002). Marine biofouling: a sticky problem. Biologist 49, 10-14.

Carfagna, S., Bottone, C., Cataletto, P. R., Petriccione, M., Pinto, G., Salbitani, G., et al. (2016). Impact of sulfur starvation in autotrophic and heterotrophic cultures of the extremophilic microalga Galdieria phlegrea (Cyanidiophyceae). Plant Cell Physiol. 57, 1890-1898. doi: 10.1093/pcp/pcw112

Chen, F., and Johns, M. R. (1996). Heterotrophic growth of Chlamydomonas reinhardtii on acetate in chemostat culture. Process Biochem. 31, 601-604. doi: 10.1016/S0032-9592(96)00006-4

Costas, E., Flores-Moya, A., Perdigones, N., Maneiro, E., Blanco, J. L., García, M. E., et al. (2007). How eukaryotic algae can adapt to the Spain's Rio Tinto: a neo-Darwinian proposal for rapid adaptation to an extremely hostile ecosystem. New Phytol. 175, 334-339. doi: 10.1111/j.1469-8137.2007.02095.x
All authors contributed to the article and approved the submitted version.

\section{FUNDING}

This work was supported by AlgaePARC, Wageningen University.

\section{SUPPLEMENTARY MATERIAL}

The Supplementary Material for this article can be found online at: https://www.frontiersin.org/articles/10.3389/fmicb.2022.820907/ full\#supplementary-material

Cuaresma, M., Casal, C., Forján, E., and Vílchez, C. (2011). Productivity and selective accumulation of carotenoids of the novel extremophile microalga Chlamydomonas acidophila grown with different carbon sources in batch systems. J. Ind. Microbiol. Biotechnol. 38, 167-177. doi: 10.1007/s10295-010-0841-3

Cuaresma, M., Janssen, M., Vílchez, C., and Wijffels, R. H. (2009). Productivity of Chlorella sorokiniana in a short light-path (SLP) panel photobioreactor under high irradiance. Biotechnol. Bioeng. 104, 352-359. doi: 10.1002/bit.22394

D'Elia, L., del Mondo, A., Santoro, M., de Natale, A., Pinto, G., and Pollio, A. (2018). Microorganisms from harsh and extreme environments: a collection of living strains at ACUF (Naples, Italy). Ecol. Quest. 29, 63-74. doi: 10.12775/ EQ.2018.023

Day, J. G., Gong, Y., and Hu, Q. (2017). Microzooplanktonic grazers-a potentially devastating threat to the commercial success of microalgal mass culture. Algal Res. 27, 356-365. doi: 10.1016/j.algal.2017.08.024

Dean, A. P., Hartley, A., McIntosh, O. A., Smith, A., Feord, H. K., Holmberg, N. H., et al. (2019). Metabolic adaptation of a Chlamydomonas acidophila strain isolated from acid mine drainage ponds with low eukaryotic diversity. Sci. Total Environ. 647, 75-87. doi: 10.1016/j.scitotenv.2018.07.445

di Cicco, M. R., Iovinella, M., Palmieri, M., Lubritto, C., and Ciniglia, C. (2021). Extremophilic microalgae Galdieria gen. for urban wastewater treatment: current state, the case of "POWER" system, and future prospects. Plants 10:2343. doi: 10.3390/plants10112343

Ferraro, G., Imbimbo, P., Marseglia, A., Illiano, A., Fontanarosa, C., Amoresano, A., et al. (2020a). A thermophilic C-phycocyanin with unprecedented biophysical and biochemical properties. Int. J. Biol. Macromol. 150, 38-51. doi: 10.1016/j. ijbiomac.2020.02.045

Ferraro, G., Imbimbo, P., Marseglia, A., Lucignano, R., Monti, D. M., and Merlino, A. (2020b). X-ray structure of C-phycocyanin from Galdieria phlegrea: determinants of thermostability and comparison with a C-phycocyanin in the entire phycobilisome. Biochim. Biophys. Acta Bioenerg. 1861:148236. doi: $10.1016 /$ j.bbabio.2020.148236

Ganuza, E., and Tonkovich, A. L. (2016). "Heliae development, LLC: an industrial approach to mixotrophy in microalgae," in Industrial Biorenewables. ed. Pablo Domínguez de María 323-339.

Gao, F., Teles, I., Wijffels, R. H., and Barbosa, M. J. (2020). Process optimization of fucoxanthin production with Tisochrysis lutea. Bioresour. Technol. 315:123894. doi: 10.1016/j.biortech.2020.123894

Gerloff-Elias, A., Barua, D., Mölich, A., and Spijkerman, E. (2006). Temperatureand $\mathrm{pH}$-dependent accumulation of heat-shock proteins in the acidophilic green alga Chlamydomonas acidophila. FEMS Microbiol. Ecol. 56, 345-354. doi: 10.1111/j.1574-6941.2006.00078.x

Gerloff-Elias, A., Spijkerman, E., and Pröschold, T. (2005). Effect of external $\mathrm{pH}$ on the growth, photosynthesis and photosynthetic electron transport of Chlamydomonas acidophila Negoro, isolated from an extremely acidic lake (pH2.6). Plant Cell Environ. 28, 1218-1229. doi: 10.1111/j.1365-3040. 2005.01357.x

Graziani, G., Schiavo, S., Nicolai, M. A., Buono, S., Fogliano, V., Pinto, G., et al. (2013). Microalgae as human food: chemical and nutritional characteristics 
of the thermo-acidophilic microalga Galdieria sulphuraria. Food Funct. 4, 144-152. doi: 10.1039/C2FO30198A

Guldfeldt, L. U., and Arneborg, N. (1998). Measurement of the effects of acetic acid and extracellular $\mathrm{pH}$ on intracellular $\mathrm{pH}$ of nonfermenting, individual saccharomyces cerevisiae cells by fluorescence microscopy. Appl. Environ. Microbiol. 64, 530-534. doi: 10.1128/AEM.64.2.530-534.1998

Henkanatte-Gedera, S. M., Selvaratnam, T., Karbakhshravari, M., Myint, M., Nirmalakhandan, N., van Voorhies, W., et al. (2017). Removal of dissolved organic carbon and nutrients from urban wastewaters by Galdieria sulphuraria: laboratory to field scale demonstration. Algal Res. 24, 450-456. doi: 10.1016/j. algal.2016.08.001

Iwamoto, H. (2004). "11 industrial production of microalgal cell-mass and secondary products-major industrial species," in Handbook of Microalgal Culture: Biotechnology and Applied Phycology. ed. Amos Richmond 255-263.

Kim, M. J., Li, Y. X., Dewapriya, P., Ryu, B., and Kim, S. K. (2013). Floridoside suppresses pro-inflammatory responses by blocking MAPK signaling in activated microglia. BMB Rep. 46, 398-403. doi: 10.5483/BMBRep.2013.46.8.237

Malavasi, V., Soru, S., and Cao, G. (2020). Extremophile microalgae: the potential for biotechnological application. J. Phycol. 56, 559-573. doi: 10.1111/jpy.12965

Martinez, F., Avendaño, M. D. C., Marco, E., and Orus, M. I. (1987). Algal population and auxotrophic adaptation in a sugar refinery wastewater environment. J. Gen. Appl. Microbiol. 33, 331-341. doi: 10.2323/jgam.33.331

Martinez-Garcia, M., and van der Maarel, M. J. E. C. (2016). Floridoside production by the red microalga Galdieria sulphuraria under different conditions of growth and osmotic stress. AMB Express 6:71. doi: 10.1186/s13568-016-0244-6

Merino, N., Aronson, H. S., Bojanova, D. P., Feyhl-Buska, J., Wong, M. L., Zhang, S., et al. (2019). Living at the extremes: extremophiles and the limits of life in a planetary context. Front. Microbiol. 10:780. doi: 10.3389/ fmicb. 2019.00780

Minoda, A., Sawada, H., Suzuki, S., Miyashita, S., Inagaki, K., Yamamoto, T., et al. (2015). Recovery of rare earth elements from the sulfothermophilic red alga Galdieria sulphuraria using aqueous acid. Appl. Microbiol. Biotechnol. 99, 1513-1519. doi: 10.1007/s00253-014-6070-3

Norton, T. A., Melkonian, M., and Andersen, R. A. (1996). Algal biodiversity. Phycologia 35, 308-326. doi: 10.2216/i0031-8884-35-4-308.1

Olivieri, G., Marzocchella, A., Andreozzi, R., Pinto, G., and Pollio, A. (2011). Biodiesel production from Stichococcus strains at laboratory scale. J. Chem. Technol. Biotechnol. 86, 776-783. doi: 10.1002/jctb.2586

Oostlander, P. C., van Houcke, J., Wijffels, R. H., and Barbosa, M. J. (2020). Optimization of Rhodomonas sp. under continuous cultivation for industrial applications in aquaculture. Algal Res. 47:101889. doi: 10.1016/j.algal.2020.101889

Oren, A. (2014). The ecology of Dunaliella in high-salt environments. J. Biol. Res. 21:23. doi: 10.1186/s40709-014-0023-y

Oslan, S. N. H., Shoparwe, N. F., Yusoff, A. H., Rahim, A. A., Chang, C. S., Tan, J. S., et al. (2021). A review on Haematococcus pluvialis bioprocess optimization of green and red stage culture conditions for the production of natural astaxanthin. Biomolecules 11:256. doi: 10.3390/biom11020256

Pollio, A., Cennamo, P., Ciniglia, C., de Stefano, M., Pinto, G., Huss, A. R., et al. (2005). Chlamydomonas pitschmannii Ettl, a little known species from thermoacidic environments. Protist 156, 287-302. doi: 10.1016/j. protis.2005.04.004

Posten, C. (2009). Design principles of photo-bioreactors for cultivation of microalgae. Eng. Life Sci. 9, 165-177. doi: 10.1002/elsc.200900003

Pulz, O., and Gross, W. (2004). Valuable products from biotechnology of microalgae. Appl. Microbiol. Biotechnol. 65, 635-648. doi: 10.1007/ s00253-004-1647-x

Rahman, D. Y., Sarian, F. D., and van der Maarel, M. J. E. C. (2020). Biomass and phycocyanin content of heterotrophic Galdieria sulphuraria $074 \mathrm{G}$ under maltodextrin and granular starches-feeding conditions. J. Appl. Phycol. 32, 51-57. doi: 10.1007/s10811-019-01957-9
Rahman, D. Y., Sarian, F. D., van Wijk, A., Martinez-Garcia, M., and van der Maarel, M. J. E. C. (2017). Thermostable phycocyanin from the red microalga Cyanidioschyzon merolae, a new natural blue food colorant. J. Appl. Phycol. 29, 1233-1239. doi: 10.1007/s10811-016-1007-0

Ryu, B. M., Li, Y. X., Kang, K. H., Kim, S. K., and Kim, D. G. (2015). Floridoside from Laurencia undulata promotes osteogenic differentiation in murine bone marrow mesenchymal cells. J. Funct. Foods 19, 505-511. doi: 10.1016/j.jff.2015.09.022

Scherhag, P., and Ackermann, J.-U. (2020). Removal of sugars in wastewater from food production through heterotrophic growth of Galdieria sulphuraria. Eng. Life Sci. 21, 233-241. doi: 10.1002/elsc.202000075

Seckbach, J. (2007). Algae and Cyanobacteria in Extreme Environments. Dordrecht: Springer.

Shrestha, R., and Weber, A. (2007). Acidothermophilic red microalga Galdieria sulphuraria: from genome to an extracellular glucoamylase active at extreme low $\mathrm{pH}$ and high temperature. J. Phycol. 43, 23-24.

Sloth, J. K., Wiebe, M. G., and Eriksen, N. T. (2006). Accumulation of phycocyanin in heterotrophic and mixotrophic cultures of the acidophilic red alga Galdieria sulphuraria. Enzym. Microb. Technol. 38, 168-175. doi: 10.1016/j. enzmictec.2005.05.010

Spijkerman, E. (2007). Phosphorus acquisition by Chlamydomonas acidophila under autotrophic and osmo-mixotrophic growth conditions. J. Exp. Bot. 58, 4195-4202. doi: 10.1093/jxb/erm276

Sydney, E. B., Schafranski, K., Barretti, B. R., Sydney, A. C. N., Zimmerman, J. F. D., Cerri, M. L., et al. (2019). Biomolecules from extremophile microalgae: from genetics to bioprocessing of a new candidate for large-scale production. Process Biochem. 87, 37-44. doi: 10.1016/j.procbio.2019.09.012

Unnithan, V., Unc, A., and Smith, G. B. (2014). Mini-review: a priori considerations for bacteria-algae interactions in algal biofuel systems receiving municipal wastewaters. Algal Res. 4, 35-40. doi: 10.1016/j.algal.2013.11.009

Uwizeye, C., Decelle, J., Jouneau, P. H., Flori, S., Gallet, B., Keck, J. B., et al. (2021). Morphological bases of phytoplankton energy management and physiological responses unveiled by 3D subcellular imaging. Nat. Commun. 12:1049. doi: $10.1038 / \mathrm{s} 41467-021-21314-0$

Van Wagenen, J., Holdt, S. L., de Francisci, D., Valverde-Pérez, B., Plósz, B. G., and Angelidaki, I. (2014). Microplate-based method for high-throughput screening of microalgae growth potential. Bioresour. Technol. 169, 566-572. doi: 10.1016/j.biortech.2014.06.096

Wan, M., Wang, Z., Zhang, Z., Wang, J., Li, S., Yu, A., et al. (2016). A novel paradigm for the high-efficient production of phycocyanin from Galdieria sulphuraria. Bioresour. Technol. 218, 272-278. doi: 10.1016/j. biortech.2016.06.045

Conflict of Interest: The authors declare that the research was conducted in the absence of any commercial or financial relationships that could be construed as a potential conflict of interest.

Publisher's Note: All claims expressed in this article are solely those of the authors and do not necessarily represent those of their affiliated organizations, or those of the publisher, the editors and the reviewers. Any product that may be evaluated in this article, or claim that may be made by its manufacturer, is not guaranteed or endorsed by the publisher.

Copyright $\odot 2022$ Abiusi, Trompetter, Pollio, Wijfels and Janssen. This is an openaccess article distributed under the terms of the Creative Commons Attribution License (CC BY). The use, distribution or reproduction in other forums is permitted, provided the original author(s) and the copyright owner $(s)$ are credited and that the original publication in this journal is cited, in accordance with accepted academic practice. No use, distribution or reproduction is permitted which does not comply with these terms. 